\title{
Bone and the Innate Immune System
}

\author{
Julia F. Charles, M.D. Ph.D ${ }^{1}$ and Mary C. Nakamura, M.D. ${ }^{2,3, *}$ \\ ${ }^{1}$ Department of Medicine, Division of Rheumatology, Allergy and Immunology, Brigham and \\ Women's Hospital, 75 Francis Street, Boston, MA, 02115 Phone: FAX: jfcharles@partners.org \\ ${ }^{2}$ Department of Medicine, Division of Rheumatology, University of California, San Francisco, 513 \\ Parnassus Avenue, San Francisco, CA, 94143 \\ ${ }^{3}$ Arthritis/Immunology Section, Veterans Affairs Medical Center, 4150 Clement Street, 111R, San \\ Francisco, CA 94121, Phone: 415 750-2104, FAX: 415 750-6920, Mary.nakamura@ucsf.edu
}

\begin{abstract}
The immune system and bone are intimately linked with significant physical and functionally related interactions. The innate immune system functions as an immediate response system to initiate protections against local challenges such as pathogens and cellular damage. Bone is a very specific microenvironment in which infectious attack is less common but repair and regeneration are ongoing and important functions. Thus in the bone the primary goal of innate immune and bone interactions is to maintain tissue integrity. Innate immune signals are critical for removal of damaged and apoptotic cells and to stimulate normal tissue repair and regeneration. In this review we focus on these innate immune mechanisms that function to regulate bone homeostasis.
\end{abstract}

\section{Keywords}

Bone; Innate immunity; Osteoclast; Osteomac; Osteocyte; Apoptosis; Autophagy; Necroptosis

\section{Introduction}

The recognition that immune cell function directly influences bone remodeling with reciprocal support and influence over immune cells by bone cells has led to the active research field of osteoimmunology. In addition to providing a structural support for the body and a reservoir for calcium, bone encases the bone marrow, a primary site for hematopoiesis and immune system development. Immune system influences on bone are diverse and have been the topic of several recent reviews, which have highlighted the effects of activation of the adaptive immune system on bone in the setting of infection, osteoporosis, cancer and autoimmunity (1-5). In this review, we address the impact of the innate immune system on

* corresponding author: Arthritis/Immunology Section, Veterans Affairs Medical Center, 4150 Clement Street, 111R, San Francisco, CA 94121.

Conflict of Interest

JF Charles declares no conflicts of interest.

Human and Animal Rights and Informed Consent

All studies by the authors involving animal and/or human subjects were performed after approval by the appropriate institutional review boards. When required, written informed consent was obtained from all participants. 
bone, particularly with respect to the role of the innate immune system in tissue repair and homeostasis.

\section{The innate immune system: source of cytokines}

The innate immune system provides an immediate, invariant response to infection and injury with the goals of limiting the spread of infection, initiating the adaptive immune response and initiating tissue repair. Innate immune cells such as macrophages and dendritic cells (DC) utilize pattern recognition receptors (PRR) to recognize local "danger signals" such as DAMPs (damage-associated molecular patterns) released by tissue damage or PAMPS (pathogen associated molecular patterns) displayed by infectious organisms. Activation via PRRs leads these cells to produce inflammatory cytokines such as TNFa, IL-1, IL-6 and interferon- $\gamma($ IFN- $\gamma)$. These inflammatory cytokines have direct effects on both osteoclasts (OC) and osteoblasts, as well as indirect effects on osteoclasts via osteoblast upregulation of RANKL, the key cytokine for osteoclastogenesis, which has been the topic of recent reviews (6-8). Other innate immune cells, natural killer cells and neutrophils, are reported to produce RANKL in inflamed synovial tissue and in response to LPS, respectively, but the physiologic significance compared to osteoblast, osteocyte and T cell derived RANKL is unclear $(9,10)$.

\section{Bone resorption: an innate immune function?}

Myeloid progenitors for osteoclasts can also differentiate to DC and macrophages $(11,12)$, suggesting the close relationship of osteoclasts to cells of the innate immune system. Interestingly, both human and mouse $\mathrm{CD} 11 \mathrm{c}^{+} \mathrm{DC}$ transdifferentiate into osteoclasts in vitro $(13,14)$ and mouse DC can contribute to osteoclast formation in vivo (15). It does not appear DC are critical for normal bone turnover as DC deficient mice do not have a bone phenotype (16), but it is possible that DC contribute to pathologic bone loss as transdifferentiation is promoted by rheumatoid synovial fluid, inflammatory cytokines and in multiple myeloma $(13,17)$.

Classic stimuli for innate immune cells also directly regulate osteoclast differentiation. For example, PAMPs can directly regulate osteoclasts via osteoclast toll like receptors (TLR), although the effect of TLR activation depends on the stage of osteoclast differentiation (18, 19). TLR activation inhibits differentiation of early osteoclast precursors but can stimulate late osteoclast differentiation and increases survival of mature osteoclasts. Activation of TLRs in osteoblasts or stromal cells stimulates production of osteoclastogenic cytokines, such as RANKL and TNF-a. Similarly, Fc $\gamma$ RIV crosslinking by immune complexes enhances osteoclast differentiation in vitro and osteoclast specific deletion of Fc $\gamma$ RIV partially protects mice from bone erosion in inflammatory arthritis (20). Osteoclasts are regulated by a number of other innate immune receptors and are able to rapidly initiate bone remodeling and calcium mobilization in response to microenvironmental signals. Thus, it can be argued that osteoclasts are innate immune cells of the bone (21).

In the bone microenvironment, infectious insults are less common but repair and regeneration are ongoing and critical functions. Ongoing bone resorption is important for bone homeostasis. Bone remodeling occurs continuously to adapt to changes in load and to 
replace damaged bone (22). The absence of osteoclast function results in osteopetrosis, but the resulting bone may be compromised due to lack of repair functions (23). Tissue repair and homeostasis requires an innate immune response, which is of particular relevance in bone.

\section{Innate Immunity and Tissue Homeostasis}

In addition to its well-recognized function as the first line of defense against pathogens, the innate immune system plays a crucial role in tissue homeostasis and repair. Tissue resident macrophages are increasingly recognized as important sources of trophic factors in tissue homeostasis and repair (24). A further critical function of the innate immune system in tissue homeostasis is active surveillance and eradication of damaged or dying cells in the local microenvironment. Cell death can occur in several ways and the innate immune system responds differently to each type of cellular damage. Macrophages are the primary scavengers removing apoptotic cells, which have ungergone programmed cell death during tissue remodeling or in response to stress. During injury, necrotic cells release DAMPs, initiating inflammatory cytokine release and influx of inflammatory cells. Resolution of inflammation is a prerequisite for tissue repair, and the innate immune system contributes in the form of alternatively activated (M2) macrophages and myeloid derived suppressor cells (MDSC) among other mechanisms. Autophagy, the degradation of cytoplasmic components in response to nutritional stress, may be the most primitive form of innate immunity and is crucial for cellular homeostasis. Autophagy can function both in direct microbial elimination and is activated by stimulation by DAMPs as well as PAMPS in the setting of infection (25). Thus, innate immune stimuli in injury or infection stimulate homeostatic mechanisms at both the cellular and tissue level.

The recent identification of bone resident tissue macrophages distributed throughout the periosteum and associated with sites of bone modeling in vivo suggests that in bone, as in other tissues, resident macrophages may contribute to tissue homeostasis. Consistent with this, these "osteomacs" promote osteoblast differentiation and mineralization in vitro and their depletion in vivo rapidly destroyed maintenance of the osteoblast bone modeling surface (26). More recently, osteomacs were shown to promote bone matrix deposition and mineralization in a bone injury model (27), suggesting that these innate immune cells are important for both basal bone homeostasis and tissue repair.

\section{Innate Immune Recognition of Cell Death and Bone}

Cell turnover is an important aspect of bone remodeling and apoptosis of osteoclasts and osteoblasts has long been suggested to contribute to bone mass regulation (28). Apoptosis or programmed cell death is an essential process that organisms use to remove unwanted or defective cells during development and tissue remodeling. Factors that activate the apoptotic death pathway include DNA damage, hypoxia and activation of death receptors. Apoptoticinducing stimuli initiate a caspase activation cascade and increased permeability of the outer mitochondrial membrane. Apoptotic cells must be cleared by the immune system and are considered immunologically silent because they do not generally stimulate production of inflammatory cytokines (29). Macrophages and/or stromal cells remove apoptotic cells by 
phagocytosis and failure of this removal is a factor leading to chronic inflammation and autoimmunity. A number of receptors have been implicated in engulfment of apoptotic cells by macrophages, dendritic cells and non-professional phagoctyes, including CD36 and the scavenger receptors (29). Mice deficient in the scavenger receptor type A locus show increased bone mass, increased femur length and decreased osteoclasts $(30,31)$. In contrast a low bone mass phenotype is seen in $C d 36^{-/}$mice with diminished osteoblast differentiation (32). Thus, it is likely that defects in removal of apoptotic cells effects bone homeostasis but the roles of specific receptors remains to be established.

Apoptosis of osteocytes, the mechanosensors of the bone, has been suggested to target osteoclastogenesis and initiate bone remodeling at specific areas of bone damage (33). Osteocyte apoptosis is induced in areas surrounding fatigue-loading microcracks, where bone remodeling is localized $(34,35)$ and caspase inhibition prevented fatigue induced cortical remodeling (36). During skeletal unloading, osteocyte apoptosis is induced and precedes osteoclastogenesis and bone loss $(37,38)$. The finding that a caspase inhibitor that blocks osteocyte apoptosis in mice abrogates bone loss due to skeletal unloading further suggests that osteocyte apoptosis is required to initiate skeletal unloading-induced bone loss (39). Other studies showed that blocking osteocyte apopotosis also blocks increased cortical bone resorption in mice after ovariectomy (40). Several studies recently demonstrated the importance of osteocyte produced-RANKL in cancellous bone remodeling. Mice deficient in RANKL specifically in osteocytes are markedly osteopetrotic despite production of RANKL by other cell types $(41,42)$. One of these studies also demonstrated that osteocyte produced RANKL was required for skeletal unloading induced bone loss (42). Interestingly, this latter finding suggests a role for osteocyte apoptosis in stimulating osteocyte production of RANKL. Studies of microcracks suggest that RANKL is expressed by healthy neighboring osteocytes rather than the apoptotic cells themselves (34). Thus, osteocyte apoptosis appears to be a key feature of bone response to diverse injuries.

Rapid clearance of apoptotic cells is implicated in maintaining tissue health and failure of clearance has been associated with autoimmunity, neuropathy, and atherosclerosis (43). Embedded in their matrix lacunae, apoptotic or dysfunctional osteocytes are inaccessible to macrophages and other professional phagocytic cells. Thus degradation of matrix by osteoclasts may be needed to remove damaged osteocytes. Osteoclasts also express engulfment receptors and are able to phagocytose apoptotic cells in vitro (44) and in vivo (45). Thus osteoclast activation in response to osteocyte apoptosis may serve to the dual function of clearance of apoptotic osteocytes and maintenance of bone homeostasis. Induction of osteocyte apoptosis in pathological bone turnover states such as estrogen deficiency, glucocorticoid use or skeletal unloading likely coopts the same cell death removal pathway and initiates osteoclast activation.

More recently an alternate type of programmed cell death, termed regulated necrosis or necroptosis, was described as a highly regulated cell death pathway, that leads to release of DAMPs and an inflammatory response (46). Necroptosis can be defined as a caspaseindependent pathway to cell death that is dependent on the receptor-interacting protein kinase 1 (RIPK1)-RIPK3 complex (47). Necroptosis can be initiated by inflammatory or injury signals including TNFa, Fas ligand, TRAIL ligand, double-stranded RNA (dsRNA), 
IFN- $\gamma$, ATP depletion, ischemia-reperfusion injury, and pathogens (48). Necroptosis leads to rapid plasma membrane permeabilization and release of cell contents with resultant exposure and release of damage-associated molecular patterns (DAMPs) (46). While the role of necroptosis has not been directly examined in bone cells, the known effects of the initiating factors such as TNFa on bone suggest that responses to necroptosis are likely also significant in regulating bone function. Due to the regulated nature of necroptosis, it will be of interest to determine if specific components of this pathway are required in distinct types of pathologic bone loss.

In contrast to controlled cell death, necrosis is considered accidental cell death due to extreme cellular physicochemical stress, damage or injury such as heat, osmotic or mechanical shock. Necrosis involves loss of membrane integrity and sudden release of intracellular content. Cellular damage releases DAMPs, which include HMGB1, IL-1a, uric acid, DNA fragments, mitochondrial content, and ATP. The release of DAMPS to the extracellular space where they stimulate other cells leads to initiation of an acute inflammatory response such as seen with sepsis, ischemic injury or trauma (49).

During bone regeneration following injury, the inflammatory cytokines and macrophages have increasingly been recognized as critical elements during normal repair. Inflammatory cytokines TNFa, IL-1, and IL-6 are expressed at the fracture site within 24 hours of injury in mouse models of bone repair (50). During early fracture repair, levels of inflammatory cytokines are biphasic with acute rise of TNFa and IL-1 at initiation and a later peak at the transition from chondrogenesis to osteogenesis during endochondral maturation (50). TNFa receptor ( $\mathrm{p} 55^{-/-} / \mathrm{p} 75^{--}$) knockout mice demonstrate delayed endochondral maturation in a delayed fracture repair model and IL-6 deficiency leads to delayed callus remodeling and mineralization $(51,52)$. Other acute inflammatory mediators such as the complement cascade have also been suggested to be important in bone regeneration (53). Complement components have been shown to regulate osteoclastogenesis however all the roles of complement in bone are not yet fully understood $(54,55)$., Thus, acute inflammation has an essential role in initiating repair, though persistent inflammation of this type is likely detrimental to bone homeostasis (56).

HMGB1 has also been implicated in stimulating tissue repair through regulation of stem cell trafficking and may similarly contribute to tissue repair in bone. During endochondral ossification HMGB1 has been shown to act as a chemotactic agent to osteoclasts and osteoblasts (57). Osteoblasts release HMGB1 in response to parathyroid hormone and recombinant HMGB1 treatment stimulates RANKL, TNFa and IL-6 expression by stromal cells and osteoblasts, thus potentially increasing the resorptive process contributing to bone repair (58-61). Consistent with this, deficiency of a HMGB1 receptor RAGE (receptor for advanced glycosylated end products) causes increased BMD and decreased osteoclast function $(62,63)$. RAGE deficiency also abrogates bone loss following ovariectomy (62).

\section{Inflammasome activation in prosthetic osteolysis}

Resolution of the initial inflammatory response is necessary for optimal wound healing and tissue repair. Prolonged inflammation is a factor in bone loss due to aging, estrogen 
deficiency and autoimmune disease $(64,65)$. Pathologic bone loss due to prolonged inflammation is also seen in models of prosthetic osteolysis (66-68). Recent studies demonstrated that orthopedic particulate debris activates myeloid cells via both TLR signaling and inflammasome activation $(69,70)$. Production of pro-inflammatory cytokines especially IL- $1 \beta$ and IL-18 is activated by a proteolytic cleavage cascade dependent on caspase-1. Activation of caspase-1 requires oligomerization of signaling proteins into a common structure termed the inflammasome. Thus, Inflammasomes are multi-protein complexes that respond to a variety of DAMPS and PAMPS by activating maturation of IL-1 $(49,71)$.

Human monocytes and mouse macrophages produce IL-1 in response to polymethylmethacrylate (PMMA) particle phagocytosis (70). In polyethylene (PE) particleinduced osteolytic lesions, TLR-2 and TLR-4 expression is elevated with a decrease in TLR-9 and both polymethylmethacrylate (PMMA) and PE particles activate macrophages via the TLR pathway, initiating secretion of TNFa and IL-6 $(72,73)$.

DAMP stimulation can activate the inflammasome cascade in macrophages and leads to production of IL-1. In a recent study by Burton and colleagues, the NALP3 inflammasome was found to be integral to the development of peri-implant osteolysis in mouse models. Cells from mice deficient in NALP3, ASC, or caspase-1 showed a decreased cytokine response to PMMA phagocytosis. PMMA particles implanted over calvaria of caspase-1 deficient mice also showed a reduced in vivo osteolytic response. The effect on bone resorption is secondary to inflammatory changes because absence of NALP3 inflammasome components does not cause a cell autonomous defect in osteoclastogenesis (70). Inflammasome activation in prosthetic osteolysis models likely contributes to osteoclast activation and the development of aseptic loosening $(69,70,74)$. Similarly, activation of the inflammasome pathway has been shown to be important in the inflammatory responses to gout, CPPD and silica crystals $(71,75)$. These data suggest that orthopedic wear debris induce and activate components of the innate immune system, leading to production of inflammatory cytokines, and downstream effects on bone homeostasis.

\section{Innate immunity, bone and resolution of inflammation}

An important component of the homeostatic response to cellular damage is to protect tissue integrity. Thus innate immune mechanisms must also be in place to lead to resolution of inflammation following cellular injury or stress (76). Apoptosis of inflammatory cells is a non-inflammatory mechanism of cell removal and plays a critical role in successful resolution of the inflammatory response. Bone matrix resorption can release TGF $\beta$ (77), which is a potent suppressor of classical macrophage activation and an important mediator of tissue repair (78). Tissue damage can promote production of glucocorticoid hormones which affects osteocyte viability, osteoclastogenesis and monocyte/macrophage polarization towards an anti-inflammatory state (79).

Inflammatory cytokines such as TNFa have long been known to increase osteoclast precursors in the bone marrow and periphery which has been thought to contribute to bone loss in inflammatory arthritis and other states of chronic inflammation (80). Interestingly, 
we recently found that osteoclast precursors in the bone marrow are phenotypically the same as cells previously described as monocytic myeloid derived suppressor cells (M-MDSC) (11). In mice, we identified a myeloid precursor population in the normal bone marrow with osteoclast and suppressor cell potential that expanded during inflammatory arthritis. The osteoclast precursors could suppress $\mathrm{CD} 4^{+}$and $\mathrm{CD} 8^{+} \mathrm{T}$ cell proliferation in vitro and in vivo. It seems likely that the expansion of these osteoclast precursors actually represents a homeostatic mechanism in response to chronic inflammation to restrain $\mathrm{T}$ cell expansion. However, the MDSC mechanism is unfortunately ineffective in the inflammatory arthritis microenvironment, and the expanded pool of precursors is available for osteoclastogenesis. Recent studies by others have similarly shown that MDSCs expanded in response to a tumor environment can also differentiate into mature and functional osteoclasts in vitro and in vivo. Studies in both a xenograft model of myeloma and a mouse model of metastatic breast cancer suggest that tumor-induced MDSCs can promote lytic lesions and bone destruction by directly serving as osteoclast precursors $(81,82)$. Human differentiated osteoclasts have also been suggested to suppress $\mathrm{T}$ cell proliferation in vitro (83). Thus, an innate immune response to dampen inflammation can have a significant effect on bone through expansion of the shared myeloid precursor for osteoclasts and monocytic myeloid derived suppressor cells.

\section{Autophagy for Cellular Homeostasis in Bone}

Autophagy is thought to be a primordial form of innate immune pathogen elimination that has acquired a function in cellular homeostasis by enabling cells to survive stress or nutrient deprivation through the self-consumption of damaged cellular organelles (25). Autophagy is also important for the clearance of protein aggregates, targeting them for degradation (84). The process of autophagy initiates autophagosome formation and proteolytic degradation of cellular organelles and protein aggregates by lysosomes, freeing energy that can be used by the cell. Autophagy is also thought to regulate apoptosis (85), thus autophagy has both prosurvival and pro-death functions. Recent studies examining autophagy in bone cells and the requirement for autophagic components in osteoclast function have highlighted the interactions between these pathways, as discussed below.

Due to the physical structure of bone, autophagy is of particular relevance for osteocytes, cells embedded in bony matrix and cartilage which both lack direct access to vascular supplies of nutrients and oxygen. The importance of autophagy in osteocytes is seen in mice with deficiency of Atg7, a critical protein for autophagy, only in osteocytes using a DMP1cre for tissue specific expression. Lack of Atg7 in osteocytes prevents autophagy, which leads to increased oxidative stress in the bones of young mice to levels or aged mice. At 6 months of age conditional Atg7 knockout mice had low bone mass at all skeletal sites, similar to elderly animals (86). The osteocyte specific Atg7 deficient animals showed abnormal bone turnover with decreased osteoclasts and decreased bone formation. Thus taken together the deficiency of autophagy in osteocytes led to skeletal changes of early aging, suggesting that autophagy may play a role to inhibit skeletal aging (86). Osteocyte autophagy is also likely to be an important contributor to pathologic changes in bone from glucocorticoid exposure. Osteocytes exposed to low dose glucocorticoids have been 
demonstrated to undergo autophagy(87), however osteocytes exposed to high dose glucocorticoids or glucocorticoids for a prolonged period of time undergo apoptosis (88).

Interestingly, differentiation of myeloid precursors to functional osteoclasts utilizes components of the autophagy pathway. DeSelm and colleagues demonstrated that proteins essential for autophagy, including Atg5, Atg7, Atg4B, and LC3, are important for the development of the secretory function of osteoclasts (89). Localization of Rab7, which is required at the osteoclast ruffled border occurs in an Atg5-dependent manner. Formation of the external phagolysosome utilizes autophagy proteins to generate polarized secretion of lysosomal contents that contributes to functional bone resorption in vitro and in vivo. Mice deficient in Atg5 in myeloid cells showed inhibited osteoclastogenesis and bone resorption and were partially protected from ovariectomy - induced bone loss (89).

The pathways of autophagy and osteoclastogenesis also converge on the scaffolding protein p62, also known as sequestosome 1 (SQSTM1), which colocalizes with the autophagic marker light chain 3 (LC3) to link polyubiquitinated protein aggregates to the autophagic machinery (90). Mutations in SQSTM1 are a known defect in some forms of familial Paget's, a disease of abnormally large and active osteoclasts $(91,92)$. SQSTM1/p62 is upregulated by RANKL stimulation and complexes with TRAF6 and the atypical PKC (93). Genetic deficiency of $p 62$ in mice leads to impaired osteoclastogenesis in vitro and in vivo (93), whereas p62 mutations seen in Paget's disease increase osteoclast sensitivity to proosteoclastogenic cytokines (94). The shared usage of intracellular signaling components further suggests the linkage of the homeostatic functions of autophagy and bone resorption.

\section{Conclusions}

Innate immune mechanisms are required for maintenance of bone homeostasis which requires clearance of apoptotic cells, utilization of autophagy and resolution of inflammation in response to cellular damage. Likely due to their common goals, bone and immune cells utilize multiple shared pathways and precursors. These interactions are necessary for normal bone development, turnover and remodeling. Dysregulation of innate immune homeostatic pathways has been implicated in a wide variety of disease states such as autoimmunity, aging and atherosclerosis and the recognition of their importance should be extended to include multiple types of pathological bone loss.

\section{Acknowledgments}

MC Nakamura has received research support from the NIH, VA, and Arthritis Foundation; speaker honorarium from the University of Oklahoma; and travel reimbursement from the International Osteo-Immunology Conference and Rheumatology Research Foundation.

\section{References}

Papers of particular interest, published recently, have been highlighted as:

•• Of major importance

- Of importance 
1. Mori G, D'Amelio P, Faccio R, Brunetti G. The Interplay between the bone and the immune system. Clinical \& developmental immunology. 2013; 2013:720504. [PubMed: 23935650]

2. Takayanagi H. Osteoimmunology and the effects of the immune system on bone. Nature reviews. Rheumatology. 2009; 5:667-676.

3. Takayanagi H. New developments in osteoimmunology. Nature reviews. Rheumatology. 2012; 8:684-689.

4. Jones D, Glimcher LH, Aliprantis AO. Osteoimmunology at the nexus of arthritis, osteoporosis, cancer, and infection. The Journal of clinical investigation. 2011; 121:2534-2542. [PubMed: 21737885]

5. Pacifici R. Role of T cells in ovariectomy induced bone loss--revisited. Journal of bone and mineral research : the official journal of the American Society for Bone and Mineral Research. 2012; 27:231-239.

6. Baker-LePain JC, Nakamura MC, Lane NE. Effects of inflammation on bone: an update. Current opinion in rheumatology. 2011; 23:389-395. [PubMed: 21532485]

7. Braun T, Zwerina J. Positive regulators of osteoclastogenesis and bone resorption in rheumatoid arthritis. Arthritis research \& therapy. 2011; 13:235. [PubMed: 21861862]

8. Zhao B, Ivashkiv LB. Negative regulation of osteoclastogenesis and bone resorption by cytokines and transcriptional repressors. Arthritis research \& therapy. 2011; 13:234. [PubMed: 21861861]

9. Soderstrom K, Stein E, Colmenero P, Purath U, Muller-Ladner U, de Matos CT, Tarner IH, Robinson WH, Engleman EG. Natural killer cells trigger osteoclastogenesis and bone destruction in arthritis. Proceedings of the National Academy of Sciences of the United States of America. 2010; 107:13028-13033. [PubMed: 20615964]

10. Chakravarti A, Raquil MA, Tessier P, Poubelle PE. Surface RANKL of Toll-like receptor 4stimulated human neutrophils activates osteoclastic bone resorption. Blood. 2009; 114:1633-1644. [PubMed: 19546479]

11. Charles JF, Hsu LY, Niemi EC, Weiss A, Aliprantis AO, Nakamura MC. Inflammatory arthritis increases mouse osteoclast precursors with myeloid suppressor function. The Journal of clinical investigation. 2012; 122:4592-4605. [PubMed: 23114597] First demonstration of shared relationship of osteoclast precursors and myeloid dervied suppressor cells.

12. Jacome-Galarza CE, Lee SK, Lorenzo JA, Aguila HL. Identification, characterization, and isolation of a common progenitor for osteoclasts, macrophages, and dendritic cells from murine bone marrow and periphery. Journal of bone and mineral research : the official journal of the American Society for Bone and Mineral Research. 2013; 28:1203-1213.

13. Rivollier A, Mazzorana M, Tebib J, Piperno M, Aitsiselmi T, Rabourdin-Combe C, Jurdic P, Servet-Delprat C. Immature dendritic cell transdifferentiation into osteoclasts: a novel pathway sustained by the rheumatoid arthritis microenvironment. Blood. 2004; 104:4029-4037. [PubMed: 15308576]

14. Alnaeeli M, Penninger JM, Teng YT. Immune interactions with CD4+ T cells promote the development of functional osteoclasts from murine CD11c+ dendritic cells. Journal of immunology. 2006; 177:3314-3326.

15. Wakkach A, Mansour A, Dacquin R, Coste E, Jurdic P, Carle GF, Blin-Wakkach C. Bone marrow microenvironment controls the in vivo differentiation of murine dendritic cells into osteoclasts. Blood. 2008; 112:5074-5083. [PubMed: 18768394]

16. McKenna HJ, Stocking KL, Miller RE, Brasel K, De Smedt T, Maraskovsky E, Maliszewski CR, Lynch DH, Smith J, Pulendran B, et al. Mice lacking flt3 ligand have deficient hematopoiesis affecting hematopoietic progenitor cells, dendritic cells, and natural killer cells. Blood. 2000; 95:3489-3497. [PubMed: 10828034]

17. Tucci M, Stucci S, Savonarola A, Ciavarella S, Cafforio P, Dammacco F, Silvestris F. Immature dendritic cells in multiple myeloma are prone to osteoclast-like differentiation through interleukin-17A stimulation. British journal of haematology. 2013; 161:821-831. [PubMed: 23594390]

18. Bar-Shavit Z. Taking a toll on the bones: regulation of bone metabolism by innate immune regulators. Autoimmunity. 2008; 41:195-203. [PubMed: 18365832] 
19. Takami M, Kim N, Rho J, Choi Y. Stimulation by toll-like receptors inhibits osteoclast differentiation. J Immunol. 2002; 169:1516-1523. [PubMed: 12133979]

20. Seeling M, Hillenhoff U, David JP, Schett G, Tuckermann J, Lux A, Nimmerjahn F. Inflammatory monocytes and Fcgamma receptor IV on osteoclasts are critical for bone destruction during inflammatory arthritis in mice. Proceedings of the National Academy of Sciences of the United States of America. 2013; 110:10729-10734. [PubMed: 23754379]

21. Wu Y, Humphrey MB, Nakamura MC. Osteoclasts - the innate immune cells of the bone. Autoimmunity. 2008; 41:183-194. [PubMed: 18365831]

22. Boyce BF, Rosenberg E, de Papp AE, Duong le T. The osteoclast, bone remodelling and treatment of metabolic bone disease. European journal of clinical investigation. 2012; 42:1332-1341. [PubMed: 22998735]

23. Del Fattore A, Cappariello A, Teti A. Genetics, pathogenesis and complications of osteopetrosis. Bone. 2008; 42:19-29. [PubMed: 17936098]

24. Chazaud B. Macrophages: Supportive cells for tissue repair and regeneration. Immunobiology. 2013

25. Deretic V, Saitoh T, Akira S. Autophagy in infection, inflammation and immunity. Nature reviews. Immunology. 2013; 13:722-737.

26. Chang MK, Raggatt LJ, Alexander KA, Kuliwaba JS, Fazzalari NL, Schroder K, Maylin ER, Ripoll VM, Hume DA, Pettit AR. Osteal tissue macrophages are intercalated throughout human and mouse bone lining tissues and regulate osteoblast function in vitro and in vivo. Journal of immunology. 2008; 181:1232-1244. First demonstration of the "osteomac" cells as tissue resident macrophages in the bone.

27. Alexander KA, Chang MK, Maylin ER, Kohler T, Muller R, Wu AC, Van Rooijen N, Sweet MJ, Hume DA, Raggatt LJ, et al. Osteal macrophages promote in vivo intramembranous bone healing in a mouse tibial injury model. Journal of bone and mineral research : the official journal of the American Society for Bone and Mineral Research. 2011; 26:1517-1532.

28. Jilka RL, Weinstein RS, Bellido T, Parfitt AM, Manolagas SC. Osteoblast programmed cell death (apoptosis): modulation by growth factors and cytokines. J Bone Miner Res. 1998; 13:793-802. [PubMed: 9610743]

29. Hochreiter-Hufford A, Ravichandran KS. Clearing the dead: apoptotic cell sensing, recognition, engulfment, and digestion. Cold Spring Harbor perspectives in biology. 2013; 5:a008748. [PubMed: 23284042]

30. Lin YL, de Villiers WJ, Garvy B, Post SR, Nagy TR, Safadi FF, Faugere MC, Wang G, Malluche $\mathrm{HH}$, Williams JP. The effect of class a scavenger receptor deficiency in bone. The Journal of biological chemistry. 2007; 282:4653-4660. [PubMed: 17166840]

31. Takemura K, Sakashita N, Fujiwara Y, Komohara Y, Lei X, Ohnishi K, Suzuki H, Kodama T, Mizuta H, Takeya M. Class A scavenger receptor promotes osteoclast differentiation via the enhanced expression of receptor activator of NF-kappaB (RANK). Biochemical and biophysical research communications. 2010; 391:1675-1680. [PubMed: 20036645]

32. Kevorkova O, Martineau C, Martin-Falstrault L, Sanchez-Dardon J, Brissette L, Moreau R. LowBone-Mass Phenotype of Deficient Mice for the Cluster of Differentiation 36 (CD36). PLOSone. 2013; 8:e77701.

33. Jilka RL, Noble B, Weinstein RS. Osteocyte apoptosis. Bone. 2013; 54:264-271. [PubMed: 23238124]

34. Kennedy OD, Herman BC, Laudier DM, Majeska RJ, Sun HB, Schaffler MB. Activation of resorption in fatigue-loaded bone involves both apoptosis and active pro-osteoclastogenic signaling by distinct osteocyte populations. Bone. 2012; 50:1115-1122. [PubMed: 22342796]

35. Verborgt O, Gibson GJ, Schaffler MB. Loss of osteocyte integrity in association with microdamage and bone remodeling after fatigue in vivo. Journal of bone and mineral research : the official journal of the American Society for Bone and Mineral Research. 2000; 15:60-67.

36. Cardoso L, Herman BC, Verborgt O, Laudier D, Majeska RJ, Schaffler MB. Osteocyte apoptosis controls activation of intracortical resorption in response to bone fatigue. Journal of bone and mineral research : the official journal of the American Society for Bone and Mineral Research. 2009; 24:597-605. 
37. Noble BS, Peet N, Stevens HY, Brabbs A, Mosley JR, Reilly GC, Reeve J, Skerry TM, Lanyon LE. Mechanical loading: biphasic osteocyte survival and targeting of osteoclasts for bone destruction in rat cortical bone. American journal of physiology. Cell physiology. 2003; 284:C934-C943. [PubMed: 12477665]

38. Aguirre JI, Plotkin LI, Stewart SA, Weinstein RS, Parfitt AM, Manolagas SC, Bellido T. Osteocyte apoptosis is induced by weightlessness in mice and precedes osteoclast recruitment and bone loss. Journal of bone and mineral research : the official journal of the American Society for Bone and Mineral Research. 2006; 21:605-615.

39. Cabahug PCLD, Kennedy OD, Majeska RJ, Tuthill A, Judex S, Shaffler MB. Inhibition of osteocyte apoptosis prevents trabecular bone loss after unloading of mouse long bone. Orthopaedic Research Society, San Antonio. 2013

40. Emerton KB, Hu B, Woo AA, Sinofsky A, Hernandez C, Majeska RJ, Jepsen KJ, Schaffler MB. Osteocyte apoptosis and control of bone resorption following ovariectomy in mice. Bone. 2010; 46:577-583. [PubMed: 19925896]

41. Nakashima T, Hayashi M, Fukunaga T, Kurata K, Oh-Hora M, Feng JQ, Bonewald LF, Kodama T, Wutz A, Wagner EF, et al. Evidence for osteocyte regulation of bone homeostasis through RANKL expression. Nature medicine. 2011; 17:1231-1234. First demonstration of the importance of osteocyte produced RANKL in bone turnover regulation.

42. Xiong J, Onal M, Jilka RL, Weinstein RS, Manolagas SC, O'Brien CA. Matrix-embedded cells control osteoclast formation. Nature medicine. 2011; 17:1235-1241. First demonstration of the importance of osteocyte produced RANKL in bone turnover regulation and demonstration the bone loss with skeletal unloading requires osteocyte produced RANKL.

43. Elliott MR, Ravichandran KS. Clearance of apoptotic cells: implications in health and disease. The Journal of cell biology. 2010; 189:1059-1070. [PubMed: 20584912]

44. Harre U, Keppeler H, Ipseiz N, Derer A, Poller K, Aigner M, Schett G, Herrmann M, Lauber K. Moonlighting osteoclasts as undertakers of apoptotic cells. Autoimmunity. 2012; 45:612-619. [PubMed: 22978425]

45. Bronckers AL, Goei W, van Heerde WL, Dumont EA, Reutelingsperger CP, van den Eijnde SM. Phagocytosis of dying chondrocytes by osteoclasts in the mouse growth plate as demonstrated by annexin-V labelling. Cell and tissue research. 2000; 301:267-272. [PubMed: 10955722]

46. Kaczmarek A, Vandenabeele P, Krysko DV. Necroptosis: the release of damage-associated molecular patterns and its physiological relevance. Immunity. 2013; 38:209-223. [PubMed: 23438821]

47. Moriwaki K, Chan FK. RIP3: a molecular switch for necrosis and inflammation. Genes \& development. 2013; 27:1640-1649. [PubMed: 23913919]

48. Chan FK. Fueling the flames: Mammalian programmed necrosis in inflammatory diseases. Cold Spring Harbor perspectives in biology. 2012; 4

49. Tang D, Kang R, Coyne CB, Zeh HJ, Lotze MT. PAMPs and DAMPs: signal 0s that spur autophagy and immunity. Immunol Rev. 2012; 249:158-175. [PubMed: 22889221]

50. Einhorn TA, Majeska RJ, Rush EB, Levine PM, Horowitz MC. The expression of cytokine activity by fracture callus. J Bone Miner Res. 1995; 10:1272-1281. [PubMed: 8585432]

51. Gerstenfeld LC, Cho TJ, Kon T, Aizawa T, Tsay A, Fitch J, Barnes GL, Graves DT, Einhorn TA. Impaired fracture healing in the absence of TNF-alpha signaling: the role of TNF-alpha in endochondral cartilage resorption. Journal of bone and mineral research : the official journal of the American Society for Bone and Mineral Research. 2003; 18:1584-1592.

52. Wallace A, Cooney TE, Englund R, Lubahn JD. Effects of interleukin-6 ablation on fracture healing in mice. Journal of orthopaedic research : official publication of the Orthopaedic Research Society. 2011; 29:1437-1442. [PubMed: 21445992]

53. Schoengraf P, Lambris JD, Recknagel S, Kreja L, Liedert A, Brenner RE, Huber-Lang M, Ignatius A. Does complement play a role in bone development and regeneration? Immunobiology. 2013; 218:1-9. [PubMed: 22464814]

54. Ignatius A, Schoengraf P, Kreja L, Liedert A, Recknagel S, Kandert S, Brenner RE, Schneider M, Lambris JD, Huber-Lang M. Complement C3a and C5a modulate osteoclast formation and 
inflammatory response of osteoblasts in synergism with IL-1beta. J Cell Biochem. 2011; 112:2594-2605. [PubMed: 21598302]

55. Tu Z, Bu H, Dennis JE, Lin F. Efficient osteoclast differentiation requires local complement activation. Blood. 2010; 116:4456-4463. [PubMed: 20709903]

56. Claes L, Recknagel S, Ignatius A. Fracture healing under healthy and inflammatory conditions. Nat Rev Rheumatol. 2012; 8:133-143. [PubMed: 22293759]

57. Taniguchi N, Yoshida K, Ito T, Tsuda M, Mishima Y, Furumatsu T, Ronfani L, Abeyama K, Kawahara K, Komiya S, et al. Stage-specific secretion of HMGB1 in cartilage regulates endochondral ossification. Molecular and cellular biology. 2007; 27:5650-5663. [PubMed: 17548469]

58. Charoonpatrapong K, Shah R, Robling AG, Alvarez M, Clapp DW, Chen S, Kopp RP, Pavalko FM, Yu J, Bidwell JP. HMGB1 expression and release by bone cells. Journal of cellular physiology. 2006; 207:480-490. [PubMed: 16419037]

59. Yang J, Shah R, Robling AG, Templeton E, Yang H, Tracey KJ, Bidwell JP. HMGB1 is a boneactive cytokine. Journal of cellular physiology. 2008; 214:730-739. [PubMed: 17786958]

60. Zhou Z, Han JY, Xi CX, Xie JX, Feng X, Wang CY, Mei L, Xiong WC. HMGB1 regulates RANKL-induced osteoclastogenesis in a manner dependent on RAGE. Journal of bone and mineral research : the official journal of the American Society for Bone and Mineral Research. 2008; 23:1084-1096.

61. Hamada Y, Kitazawa S, Kitazawa R, Kono K, Goto S, Komaba H, Fujii H, Yamamoto Y, Yamamoto H, Usami M, et al. The effects of the receptor for advanced glycation end products (RAGE) on bone metabolism under physiological and diabetic conditions. Endocrine. 2010; 38:369-376. [PubMed: 20972729]

62. Ding KH, Wang ZZ, Hamrick MW, Deng ZB, Zhou L, Kang B, Yan SL, She JX, Stern DM, Isales $\mathrm{CM}$, et al. Disordered osteoclast formation in RAGE-deficient mouse establishes an essential role for RAGE in diabetes related bone loss. Biochemical and biophysical research communications. 2006; 340:1091-1097. [PubMed: 16403440]

63. Zhou Z, Immel D, Xi CX, Bierhaus A, Feng X, Mei L, Nawroth P, Stern DM, Xiong WC. Regulation of osteoclast function and bone mass by RAGE. The Journal of experimental medicine. 2006; 203:1067-1080. [PubMed: 16606672]

64. Redlich K, Smolen JS. Inflammatory bone loss: pathogenesis and therapeutic intervention. Nature reviews. Drug discovery. 2012; 11:234-250.

65. Weitzmann MN, Pacifici R. Estrogen deficiency and bone loss: an inflammatory tale. The Journal of clinical investigation. 2006; 116:1186-1194. [PubMed: 16670759]

66. Ollivere B, Wimhurst JA, Clark IM, Donell ST. Current concepts in osteolysis. The Journal of bone and joint surgery. British volume. 2012; 94:10-15. [PubMed: 22219240]

67. Abu-Amer Y, Darwech I, Clohisy JC. Aseptic loosening of total joint replacements: mechanisms underlying osteolysis and potential therapies. Arthritis Res Ther. 2007; 9(Suppl 1):S6. [PubMed: 17634145]

68. Goodman SB, Gibon E, Yao Z. The basic science of periprosthetic osteolysis. Instr Course Lect. 2013; 62:201-206. [PubMed: 23395025]

69. Hallab NJ, Jacobs JJ. Biologic effects of implant debris. Bull NYU Hosp Jt Dis. 2009; 67:182-188. [PubMed: 19583551]

70. Burton L, Paget D, Binder NB, Bohnert K, Nestor BJ, Sculco TP, Santambrogio L, Ross FP, Goldring SR, Purdue PE. Orthopedic wear debris mediated inflammatory osteolysis is mediated in part by NALP3 inflammasome activation. Journal of orthopaedic research : official publication of the Orthopaedic Research Society. 2013; 31:73-80. [PubMed: 22933241] Demonstration that particle induced osteolysis is mediated by inflammasome activation.

71. Martinon F, Petrilli V, Mayor A, Tardivel A, Tschopp J. Gout-associated uric acid crystals activate the NALP3 inflammasome. Nature. 2006; 440:237-241. [PubMed: 16407889]

72. Valladares RD, Nich C, Zwingenberger S, Li C, Swank KR, Gibon E, Rao AJ, Yao Z, Goodman SB. Toll-like receptors- 2 and 4 are overexpressed in an experimental model of particle-induced osteolysis. Journal of biomedical materials research. Part A. 2013 
73. Frick C, Dietz AC, Merritt K, Umbreit TH, Tomazic-Jezic VJ. Effects of prosthetic materials on the host immune response: evaluation of polymethyl-methacrylate (PMMA), polyethylene (PE), and polystyrene (PS) particles. Journal of long-term effects of medical implants. 2006; 16:423433. [PubMed: 17956209]

74. Atkins GJ, Haynes DR, Howie DW, Findlay DM. Role of polyethylene particles in peri-prosthetic osteolysis: A review. World J Orthop. 2011; 2:93-101. [PubMed: 22474627]

75. Hornung V, Bauernfeind F, Halle A, Samstad EO, Kono H, Rock KL, Fitzgerald KA, Latz E. Silica crystals and aluminum salts activate the NALP3 inflammasome through phagosomal destabilization. Nature immunology. 2008; 9:847-856. [PubMed: 18604214]

76. Ortega-Gomez A, Perretti M, Soehnlein O. Resolution of inflammation: an integrated view. EMBO Mol Med. 2013; 5:661-674. [PubMed: 23592557]

77. Tang Y, Wu X, Lei W, Pang L, Wan C, Shi Z, Zhao L, Nagy TR, Peng X, Hu J, et al. TGF-beta1induced migration of bone mesenchymal stem cells couples bone resorption with formation. Nature medicine. 2009; 15:757-765.

78. Wan M, Li C, Zhen G, Jiao K, He W, Jia X, Wang W, Shi C, Xing Q, Chen YF, et al. Injuryactivated transforming growth factor beta controls mobilization of mesenchymal stem cells for tissue remodeling. Stem Cells. 2012; 30:2498-2511. [PubMed: 22911900]

79. Molina PE. Neurobiology of the stress response: contribution of the sympathetic nervous system to the neuroimmune axis in traumatic injury. Shock. 2005; 24:3-10. [PubMed: 15988314]

80. Xing L, Schwarz EM, Boyce BF. Osteoclast precursors, RANKL/RANK, and immunology. Immunol Rev. 2005; 208:19-29. [PubMed: 16313338]

81. Sawant A, Deshane J, Jules J, Lee CM, Harris BA, Feng X, Ponnazhagan S. Myeloid-derived suppressor cells function as novel osteoclast progenitors enhancing bone loss in breast cancer. Cancer research. 2013; 73:672-682. [PubMed: 23243021]

82. Zhuang J, Zhang J, Lwin ST, Edwards JR, Edwards CM, Mundy GR, Yang X. Osteoclasts in multiple myeloma are derived from Gr-1+CD11b+myeloid-derived suppressor cells. PloS one. 2012; 7:e48871. [PubMed: 23173040]

83. Grassi F, Manferdini C, Cattini L, Piacentini A, Gabusi E, Facchini A, Lisignoli G. T cell suppression by osteoclasts in vitro. Journal of cellular physiology. 2011; 226:982-990. [PubMed: 20857429]

84. Funderburk SF, Marcellino BK, Yue Z. Cell "self-eating" (autophagy) mechanism in Alzheimer's disease. Mt Sinai J Med. 2010; 77:59-68. [PubMed: 20101724]

85. Bincoletto C, Bechara A, Pereira GJ, Santos CP, Antunes F, Peixoto da- Silva J, Muler M, Gigli RD, Monteforte PT, Hirata H, et al. Interplay between apoptosis and autophagy, a challenging puzzle: New perspectives on antitumor chemotherapies. Chem Biol Interact. 2013; 206:279-288. [PubMed: 24121004]

86. Onal M, Piemontese M, Xiong J, Wang Y, Han L, Ye S, Komatsu M, Selig M, Weinstein RS, Zhao H, et al. Suppression of autophagy in osteocytes mimics skeletal aging. The Journal of biological chemistry. 2013; 288:17432-17440. [PubMed: 23645674]

87. Xia X, Kar R, Gluhak-Heinrich J, Yao W, Lane NE, Bonewald LF, Biswas SK, Lo WK, Jiang JX. Glucocorticoid-induced autophagy in osteocytes. Journal of bone and mineral research : the official journal of the American Society for Bone and Mineral Research. 2010; 25:2479-2488.

88. Jia J, Yao W, Guan M, Dai W, Shahnazari M, Kar R, Bonewald L, Jiang JX, Lane NE. Glucocorticoid dose determines osteocyte cell fate. FASEB journal : official publication of the Federation of American Societies for Experimental Biology. 2011; 25:3366-3376. [PubMed: 21705669]

89. DeSelm CJ, Miller BC, Zou W, Beatty WL, van Meel E, Takahata Y, Klumperman J, Tooze SA, Teitelbaum SL, Virgin HW. Autophagy proteins regulate the secretory component of osteoclastic bone resorption. Developmental cell. 2011; 21:966-974. [PubMed: 22055344] First demonstration of the role for autophagy proteins in osteoclast development.

90. Komatsu M, Waguri S, Koike M, Sou YS, Ueno T, Hara T, Mizushima N, Iwata J, Ezaki J, Murata $\mathrm{S}$, et al. Homeostatic levels of p62 control cytoplasmic inclusion body formation in autophagydeficient mice. Cell. 2007; 131:1149-1163. [PubMed: 18083104] 
91. Laurin N, Brown JP, Morissette J, Raymond V. Recurrent mutation of the gene encoding sequestosome 1 (SQSTM1/p62) in Paget disease of bone. American journal of human genetics. 2002; 70:1582-1588. [PubMed: 11992264]

92. Hocking LJ, Lucas GJ, Daroszewska A, Mangion J, Olavesen M, Cundy T, Nicholson GC, Ward L, Bennett ST, Wuyts W, et al. Domain-specific mutations in sequestosome 1 (SQSTM1) cause familial and sporadic Paget's disease. Human molecular genetics. 2002; 11:2735-2739. [PubMed: 12374763]

93. Duran A, Serrano M, Leitges M, Flores JM, Picard S, Brown JP, Moscat J, Diaz-Meco MT. The atypical PKC-interacting protein p62 is an important mediator of RANK-activated osteoclastogenesis. Developmental cell. 2004; 6:303-309. [PubMed: 14960283]

94. Kurihara N, Hiruma Y, Zhou H, Subler MA, Dempster DW, Singer FR, Reddy SV, Gruber HE, Windle JJ, Roodman GD. Mutation of the sequestosome 1 (p62) gene increases osteoclastogenesis but does not induce Paget disease. The Journal of clinical investigation. 2007; 117:133-142. [PubMed: 17187080] 